\title{
Article \\ Point Prevalence Survey of Antimicrobial Utilization in Ghana's Premier Hospital: Implications for Antimicrobial Stewardship
}

\author{
Daniel Ankrah ${ }^{1, * \mathbb{D}}$, Helena Owusu ${ }^{1}$, Asiwome Aggor ${ }^{1}$, Anthony Osei ${ }^{1}$, Agneta Ampomah ${ }^{1}$, Mark Harrison ${ }^{1} \mathbb{D}_{,}$ \\ Frempomaa Nelson ${ }^{1}$, Grace Owusu Aboagye ${ }^{1}$, Priscilla Ekpale ${ }^{1}$, Jennifer Laryea ${ }^{1}$, Julia Selby ${ }^{1}$, Serwaa Amoah ${ }^{1}$, \\ Linda Lartey ${ }^{1}$, Okaikor Addison ${ }^{1}$, Elizabeth Bruce ${ }^{1}$, Joyce Mahungu ${ }^{2}$ and Mariyam Mirfenderesky ${ }^{2}$ \\ 1 Korle-Bu Teaching Hospital, Accra GA-221-1570, Ghana; h.owusu@kbth.gov.gh (H.O.); \\ Waggor23@yahoo.com (A.A.); tonyosei3@gmail.com (A.O.); agneta_ampomah@yahoo.com (A.A.); \\ markharry02@yahoo.com (M.H.); f.nelson@kbth.gov.gh (F.N.); g.aboagye@kbth.gov.gh (G.O.A.); \\ priscillaekpale@gmail.com (P.E.); jencoke@hotmail.com (J.L.); julinat@yahoo.com (J.S.); \\ s.amoah02@kbth.gov.gh (S.A.); linlartey@gmail.com (L.L.); o.addison@kbth.gov.gh (O.A.); \\ lizzybruce59@yahoo.com (E.B.) \\ 2 North Middlesex University Hospital NHS Trust, London N18 1QX, UK; joyce.mahungu@nhs.net (J.M.); \\ mariyam.mirfenderesky@nhs.net (M.M.) \\ check for \\ updates \\ * Correspondence: d.ankrah@kbth.gov.gh
}

Citation: Ankrah, D.; Owusu, H.; Aggor, A.; Osei, A.; Ampomah, A.; Harrison, M.; Nelson, F.; Aboagye, G.O.; Ekpale, P.; Laryea, J.; et al. Point Prevalence Survey of Antimicrobial Utilization in Ghana's Premier Hospital: Implications for Antimicrobial Stewardship. Antibiotics 2021, 10, 1528. https://doi.org/10.3390/ antibiotics 10121528

Academic Editors: Rabia Hussain, Jaya Muneswarao and Zaheer Ud-Din Babar

Received: 27 October 2021 Accepted: 8 December 2021 Published: 14 December 2021

Publisher's Note: MDPI stays neutral with regard to jurisdictional claims in published maps and institutional affiliations.

Copyright: (c) 2021 by the authors. Licensee MDPI, Basel, Switzerland. This article is an open access article distributed under the terms and conditions of the Creative Commons Attribution (CC BY) license (https:// creativecommons.org/licenses/by/ $4.0 /)$.

\begin{abstract}
The first comprehensive point prevalence survey at the Korle Bu Teaching Hospital (KBTH) was performed as part of the 2019 Global Point Prevalence Survey (Global-PPS) on antimicrobials. The aim was to establish a PPS baseline for the whole hospital and to identify required stewardship interventions. The PPS was conducted over three days in June 2019 using the GLOBAL-PPS standardized method for surveillance of antimicrobial utilization in hospitals to evaluate antimicrobial prescribing. In all, 988 patients were admitted to 69 wards. Overall antimicrobial prevalence was $53.3 \%$. More community-acquired infections (CAI) were treated empirically compared to health-care associated infections ( $94.0 \%$ vs. $86.1 \%$ respectively, $p=0.002)$. Main indications for prescribing antimicrobials were pneumonia (18.4\%), skin and soft tissue infections (11.4\%) and sepsis (11.1\%). Among antimicrobials, systemic antibiotics accounted for $83.5 \%$, of which amoxicillin with beta-lactam inhibitor $(17.5 \%)$, metronidazole $(11.8 \%)$ and ceftriaxone $(11.5 \%)$ dominated. Guideline compliance was $89.0 \%$. Stop/review dates were completed in $33.4 \%$ and documented reason was recorded in $53.0 \%$ of all prescriptions. If the findings in this PPS can be addressed antimicrobial stewardship at the KBTH stands to improve significantly.
\end{abstract}

Keywords: point prevalence survey; CwPAMS; antimicrobial stewardship; Korle Bu Teaching Hospital; Ghana

\section{Introduction}

Resistance to antimicrobial medicines and the resultant loss of their effectiveness and treatment failure has become a frightening global health problem [1]. Resistant infections lead to substantial economic burden, morbidity and mortality [2,3]. Resistant infections were responsible for 25,000 deaths per year with a cost of EUR 1.5 billion to the health system in Europe [3]. When resistance to first-line antimicrobial drugs occurs, more expensive therapies may be used, and longer duration of treatment and hospitalized care are usually required [2]. Globally, there is significant resistance to both old and new anti-microbial drugs, including third generation cephalosporins, carbepenems and fluoroquinolones [4,5], yielding a phenomenon of hard-to-treat infections.

In sub-Saharan Africa, paucity of evidence on antimicrobial resistance (AMR) reflects an underestimated magnitude of the problem, but in countries where data is available, 
substantial AMR has been found with a rate of 100 percent among some bacteria [6,7]. Resistance to third generation cephalosporins, fluoroquinolones, penicillins, chloramphenicol, nalidixic acid and co-trimoxazole in sub-Saharan Africa [8-11] has created a challenge for the treatment of infections.

Several factors contribute to antimicrobial resistance. These include inappropriate antimicrobial use and lack of surveillance systems contributing significantly to the spread of antimicrobial resistance. Poor infection prevention and control in healthcare facilities, lack of available, affordable and rapid diagnostic tests, and low-quality medicines are other factors that influence antimicrobial resistance [2,12]. Disparities in proper use of antibiotics, infection treatment and hygiene practices, infectious disease burden and availability of first- and second-line drugs contribute to geographical differences in AMR [12,13].

Antimicrobial consumption contributes to AMR, and the volume of antimicrobial consumption influences resistance. Global antibiotic consumption has grown in recent years with low- and middle-income countries having the highest increase [14]. Between 2000 and 2010 antibiotic, use rose by $30 \%$, and the rise in consumption for the treatment of infections such as pneumonia is expected to continue. Heavy antibiotic use by hospitals generates some of the most dangerous and difficult-to-treat infections [15]. Globally, one-third of hospitalized patients receive at least one antimicrobial prescription, and about $90 \%$ of antimicrobials prescribed are systemic antibiotics [16]. Penicillins with $\beta$-lactamase inhibitors, third-generation cephalosporins and fluoroquinolones are the most frequently prescribed antibiotics for hospitalised patients [16]. Only one-fifth of antimicrobial medicines prescribed for hospitalized patients target a specific micro-organism [16]. Recent data show that a significant proportion of prescriptions do not specify duration of treatment and reason for use [16]. However, significant variations exist in antimicrobial use between regions across the globe. Africa is the region with the highest antimicrobial use, predominantly for community acquired infections. Antimicrobial medicines are prescribed for half of hospitalized patients in Africa, and in some countries, antimicrobial use is as high as 75 percent [16]. Further, Africa has the highest use of antimicrobial drugs without reason and the lowest targeted use for resistant organisms [16]. Ghana, similar to many sub-Saharan African countries, has limited evidence on antimicrobial drug use in hospitalized patients.

In Ghana, AMR is prevalent, with rates exceeding 75 percent by some organisms [17]. Methicillin resistant staphylococcus aureus (MRSA), streptococci, salmonella, and E. coli have demonstrated high resistance to antibiotics in Ghana [17]. Low susceptibility of bacteria to antibiotics such as tetracycline, co-trimoxazole, nalidixic acid and some penicillins, and emerging resistance to quinolones, cephalosporins, gentamycin and carbapenems in Ghana $[17,18]$ is threatening morbidity and mortality outcomes of infectious diseases.

To provide feedback on antimicrobial use and associated resistance and to assess the effect of interventions and improve antimicrobial decision making, surveillance systems must be implemented as part of antimicrobial stewardship programmes [19-21]. Surveillance as part of stewardship programmes improves stewardship interventions such as promoting guideline adherence in empirical treatment [22,23]. Collecting hospital antimicrobial data and implementing informed interventions for optimal antibiotic use in hospitals has significant potential to reduce antimicrobial resistance at local, national, regional and global levels.

Antibiotic use data collection methods in hospitals allow standardization and comparison of antimicrobial use between hospitals, districts, countries, and regions. A typical example is the antimicrobial point prevalence survey (PPS). The PPS enables data collection with minimized workload and resource requirements at a specific time point, and it is already in use in hospitals [24]. The Global Point Prevalence Survey (Global-PPS) of antimicrobial drug use and resistance is suited for resource-limited (low- and middle-income) countries and allows comparison of data with high-income countries.

Similar to many sub-Saharan African countries, limited evidence on antimicrobial use with standardized surveillance methods in Ghanaian hospitals stifles the provision of timely and efficient feedback to the health system, and adversely affects the development 
of evidence-based local antimicrobial stewardship programmes and other interventions aimed at reducing antimicrobial resistance. This study, which is the first comprehensive antimicrobial survey at the Korle Bu Teaching Hospital (KBTH), used the PPS method and was a partnership between Korle-Bu Teaching Hospital from Ghana and the North Middlesex University Hospital (NMUH) from the UK. It was part of the 2019 Global Point Prevalence Survey (Global-PPS) on antimicrobials.

\section{Results}

\subsection{Antimicrobial Prevalence}

Over the course of 3 days, 988 patients on 69 wards were surveyed, and 527 patients received a total of 967 antimicrobials, giving an overall antimicrobial prevalence of $53.3 \%$ (Table 1). One hundred and eighty-two patients (35\%) received one antimicrobial, 263 patients $(50 \%)$ received two antimicrobials, and 82 patients $(15 \%)$ received three or more antimicrobials.

Table 1. Antimicrobial prevalence by ward type.

\begin{tabular}{cc}
\hline Ward & \% Treated (Number Treated) \\
\hline General or mixed Adult ICU & $100.0(7)$ \\
General or mixed Adult MW & $53.6(246)$ \\
General or mixed Adult SW & $50.0(162)$ \\
Haematology-Oncology PMW & $47.6(10)$ \\
Neonatal Intensive Care Unit & $47.7(41)$ \\
Paediatric MW & $76.3(45)$ \\
Paediatric SW & $50.0(16)$ \\
\hline Antimicrobial prevalence & $53.3(527)$ \\
\hline
\end{tabular}

Abbreviations: ICU: intensive care unit, MW: medical ward, SW: surgical ward, PMW: paediatric medical ward).

After the intensive care wards, the paediatric medical wards had the highest antimicrobial prevalence at $76.3 \%$ (Table 1 ). The majority of patients received antimicrobials via the intravenous route of administration (62.5\%).

\subsection{Patient Demographics}

Of the 527 patients treated with antimicrobials, $72 \%$ were adults ( $\geq 18$ years), and $28 \%$ were children or neonates, of which $56 \%$ were 24 months or younger (Table 2). The total number of children exceeds that on the dedicated paediatrics wards, as children may be based on adult wards, usually housed with adult females, particularly on specialist units.

Table 2. Demographics of treated patients.

\begin{tabular}{|c|c|c|c|c|c|}
\hline \multicolumn{5}{|c|}{ Patients } & \multirow{2}{*}{$\begin{array}{c}\text { Total } 527 \\
(72 \%) \\
\end{array}$} \\
\hline & Adult & & & 379 & \\
\hline & Female & Male & Unknown & & \\
\hline$\geq 60$ years & 210 & 104 & \multirow{2}{*}{1} & 315 & $(83 \%)$ \\
\hline$>60$ years & 25 & 39 & & 64 & $(17 \%)$ \\
\hline Median age in yrs (iqr *) & $34(16)$ & $45(29)$ & & & \\
\hline \multicolumn{4}{|c|}{ Children $<18$ years } & 148 & $(28 \%)$ \\
\hline & Female & Male & Unknown & & \\
\hline$<18$ years & 18 & 32 & & 50 & $(34 \%)$ \\
\hline$<5$ years & 8 & 7 & & 15 & $(10 \%)$ \\
\hline$<24$ months & 41 & 41 & \multirow{2}{*}{1} & \multirow{2}{*}{83} & \multirow{2}{*}{$(56 \%)$} \\
\hline Median age in years (iqr) & $0.3(7)$ & $1.5(8)$ & & & \\
\hline
\end{tabular}


Sixty-two percent of treated adult inpatients were female, with an average age of 38 years compared with 48 years for males. The hospital has a large obstetric service with a head count of 229 at the time of the survey, of which 110 were receiving at least one antimicrobial, accounting for $29 \%$ of the total antimicrobial consumption in the adult population.

\subsection{Treatment Indications}

2.3.1. Community-Acquired versus Healthcare Associated Infections

Forty-one percent $(41 \%)$ and $15 \%$ of antimicrobials were prescribed for communityacquired (CAI) and healthcare-associated infections (HAI), respectively. Of these, $6 \%$ of CAI, versus $13.9 \%$ of HAI ( $p=0.002)$, were targeted therapies (Table 3 ).

Table 3. The proportion of antimicrobials for empirical versus targeted treatment per therapeutic use (CAI or HAI).

\begin{tabular}{ccccccc}
\hline & \multicolumn{2}{c}{ Empirical } & \multicolumn{2}{c}{ Targeted } & \multicolumn{2}{c}{ Total } \\
\hline & $\mathrm{N}$ & $\%$ & $\mathrm{~N}$ & $\%$ & $\mathrm{~N}$ & $\%$ \\
\hline CAI & 374 & 94.0 & 24 & 6.0 & 398 & 73.4 \\
\hline HAI & 124 & 86.1 & 20 & 13.9 & 144 & 26.6 \\
\hline & 498 & & 44 & & 542 & \\
\hline
\end{tabular}

Abbreviations: CAI: community-acquired infection, HAI: healthcare-associated infection.

\subsubsection{Prophylactic Antimicrobials}

Thirty-six percent of all prescribed antimicrobials $(n=967)$ were for prophylactic use, of which $91.4 \%(n=318)$ were used for surgical prophylaxis. One hundred and eighty-four patients (out of the 527 surveyed) were prescribed antimicrobials for surgical prophylaxis, of which $78.0 \%, 13.0 \%$ and $9.0 \%$ received treatment for more than one day, one day and a single dose, respectively.

The use of prophylactic agents in obstetric and gynaecological surgery comprised 15\% of overall prescriptions. One hundred and ten out of 229 (48.0\%) obstetric patients were prescribed antimicrobial therapy, of which $75 \%$ was for prophylaxis post-surgery, with the majority of prescriptions lasting more than one day $(64 \%)$.

\subsubsection{Most Common Diagnoses Treated with Therapeutic Antimicrobials}

The most common diagnosis requiring therapeutic antimicrobials was pneumonia, followed by treatment for skin and soft tissue infections (Table 4) and sepsis.

\subsection{Antibiotic Quality Indicators by Activity}

Documentation of diagnosis/indication in the patients notes ranged from $76.1 \%$ in medicine, to $41.2 \%$ in ICU (Table 4). Whilst antimicrobials were compliant with guidelines in $80-90 \%$ of cases, lack of guidelines was documented in all units, with almost one-third of surgical prescriptions written without a current guideline. Prescriptions had a current stop or review date in less than $50 \%$ of cases across all activities and was lowest in the ICU at $11.8 \%$.

\subsection{Antibacterial Resistance}

Forty-five patients had targeted therapy, with multi-drug resistance detected in $57.8 \%$ of isolates, comprising $4.9 \%$ of all treated inpatients (Table 4 ).

\subsection{Antimicrobial Class}

Nine hundred and sixty-seven (967) individual prescriptions were recorded, with $83.5 \%$ comprising antibacterials for systemic use (Table 5). Accounting for 18.3\% (177/967) of prescriptions, metronidazole was the single most common antibiotic prescribed (ATC codes J01XD and P01AB). Antimicrobials in amount of 3.0\%, 2.1\%, 1.1\% and 1.0\% were prescribed as treatments for malaria, HIV/AIDS, fungal disease (triazole derivatives), and Mycobacterium tuberculosis, respectively. 
Table 4. Various characteristics of the PPS.

\begin{tabular}{|c|c|c|}
\hline Characteristic & Number & $(\%)$ \\
\hline \multicolumn{3}{|l|}{ Ten commonest diagnoses treated with antimicrobials } \\
\hline Pneumonia & 58 & 18.4 \\
\hline Skin and soft tissue & 36 & 11.4 \\
\hline Sepsis & 35 & 11.1 \\
\hline Upper respiratory tract infection & 25 & 7.9 \\
\hline Malaria & 24 & 7.6 \\
\hline Infection of central nervous system & 22 & 7.0 \\
\hline Obstetrics/gynaecology infection & 22 & 7.0 \\
\hline Bone and joint infection & 15 & 4.8 \\
\hline Gastro-intestinal infection & 14 & 4.4 \\
\hline Intra-abdominal sepsis & 10 & 3.2 \\
\hline \multicolumn{3}{|l|}{ Treatment according to biomarkers $(n=527)$} \\
\hline No & 502 & 95.3 \\
\hline Yes & 25 & 4.7 \\
\hline \multirow{2}{*}{\multicolumn{3}{|c|}{ Antibiotic quality indicators by department }} \\
\hline & & \\
\hline Reason in notes & 235 & 76.1 \\
\hline Guidelines missing & 79 & 25.6 \\
\hline Guideline compliant & 122 & 85.9 \\
\hline Stop/review date & 119 & 38.5 \\
\hline \multicolumn{3}{|l|}{ Surgical } \\
\hline Reason in notes & 183 & 44.3 \\
\hline Guidelines missing & 127 & 30.8 \\
\hline Guideline compliant & 135 & 83.3 \\
\hline Stop/review date & 206 & 49.9 \\
\hline \multicolumn{3}{|l|}{ Intensive care unit } \\
\hline Reason in notes & 35 & 41.2 \\
\hline Guidelines missing & 11 & 12.9 \\
\hline Guideline compliant & 38 & 92.7 \\
\hline Stop/review date & 10 & 11.8 \\
\hline \multicolumn{3}{|l|}{ Patients with isolated multi-drug resistant pathogen } \\
\hline Third generation cephalosporin resistant (TGCR) & 2 & 4.4 \\
\hline Carbapenem-resistant enterobacteriaceae & 2 & 4.4 \\
\hline Carbapenem-resistant non fermentor Gram-negative bacilli & 2 & 4.4 \\
\hline ESBL-producing Enterobacteriaceae & 7 & 15.6 \\
\hline ESBL-producing Enterobacteriaceae-TGCR & 1 & 2.2 \\
\hline No MDR recorded & 19 & 42.2 \\
\hline Targeted treatment against other MDR organisms & 10 & 22.2 \\
\hline Vancomycin-resistant enterobacteriaceae (VRE) & 2 & 4.4 \\
\hline
\end{tabular}

Table 5. Total systemic antimicrobials prescribed by class (WHO ATC classification, 2020).

\begin{tabular}{cccc}
\hline ATC Code & Total Systemic Antimicrobials & No (\%) \\
\hline J01 & Antibacterials for systemic use & 807 & $83.5 \%$ \\
P01AB & Nitroimidazole derivatives & 83 & $8.6 \%$ \\
P01B & Antimalarials & 29 & $3.0 \%$ \\
& P01B & 28 & \\
J02 & 1 & $1.0 \%$ \\
P01BB & 10 & $1.0 \%$ \\
J05 & Antimycotics for systemic use & 10 & $2.1 \%$ \\
& J02AC & & \\
& Antimycobacterials & 20 & \\
J04AM & 9 & $0.7 \%$ \\
A07AA & Antivirals for systemic use & 6 & $0.1 \%$ \\
D01 & J05AR & 4 & \\
& J05AF & 1 & $100 \%$
\end{tabular}

P01B: artemisinin and derivatives including combinations, P01BB: biguanides, J02AC: triazole derivatives, J04AM: combinations of drugs for treatment of tuberculosis, J05AR: antivirals for treatment of HIV infections, combinations, J05AF: nucleoside and nucleotide reverse transcriptase inhibitors, J05AG: non-nucleoside reverse transcriptase inhibitors, J05AB: nucleosides and nucleotides excl. reverse transcriptase inhibitors. 


\subsubsection{Antibacterials for Systemic Use (Therapeutic and Prophylactic)}

After metronidazole (J01XD and P01AB), penicillins with beta-lactamase inhibitors were the most common antibiotic for systemic use and were prescribed followed by second and third generation cephalosporins, fluoroquinolones, beta-lactamase resistant penicillins and aminoglycosides (Table 6).

Table 6. Antibacterials for Systemic Use (Therapeutic and Prophylactic).

\begin{tabular}{cc}
\hline Therapeutic Prescription & No \\
\hline Penicillins with beta-lactamase inhibitor & 141 \\
3rd gen cephalosporins & 113 \\
2nd gen cephalosporins & 86 \\
Beta-lactamase resistant penicillins & 67 \\
Beta-lactamase sensitive penicillins & 12 \\
Penicillins with extended spectrum & 8 \\
Imidazole derivatives & 95 \\
Fluoroquinolones & 86 \\
Aminoglycosides & 66 \\
Lincosamides & 62 \\
Macrolides & 28 \\
Carbapenems & 19 \\
Co-trimoxazole & 17 \\
Tetracyclines & 3 \\
Glycopeptide antibacterials & 2 \\
Combinations of antimicrobials & 1 \\
Nitrofuran derivatives & 1 \\
\hline
\end{tabular}

\subsubsection{Proportional Antibiotic Use by Class on Ward}

Proportional antibiotic use by class on the neonatal, paediatric, adult medical and surgical wards, and the top antibiotic indications disaggregated according to class are shown in Figures 1 and 2.

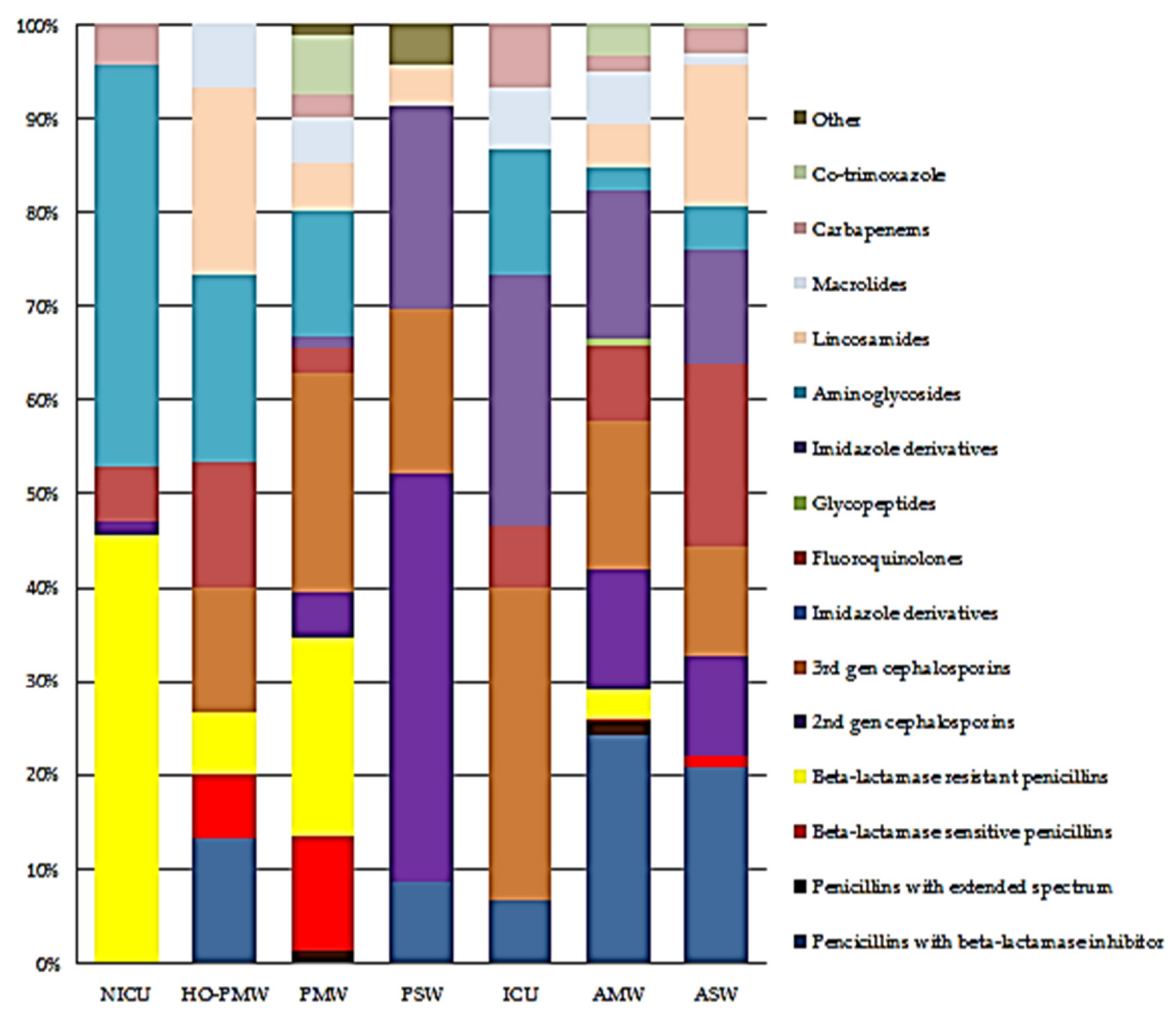

Figure 1. Proportional antibiotic use (J01) by class on wards. Abbreviations: NICU: neonatal intensive care unit, HO-PMW: haematology-oncology-paediatric medical ward, PMW: paediatric medical ward, PSW: paediatric surgical ward, ICU: intensive care unit, AMW: adult medical ward, ASW: adult surgical ward. 


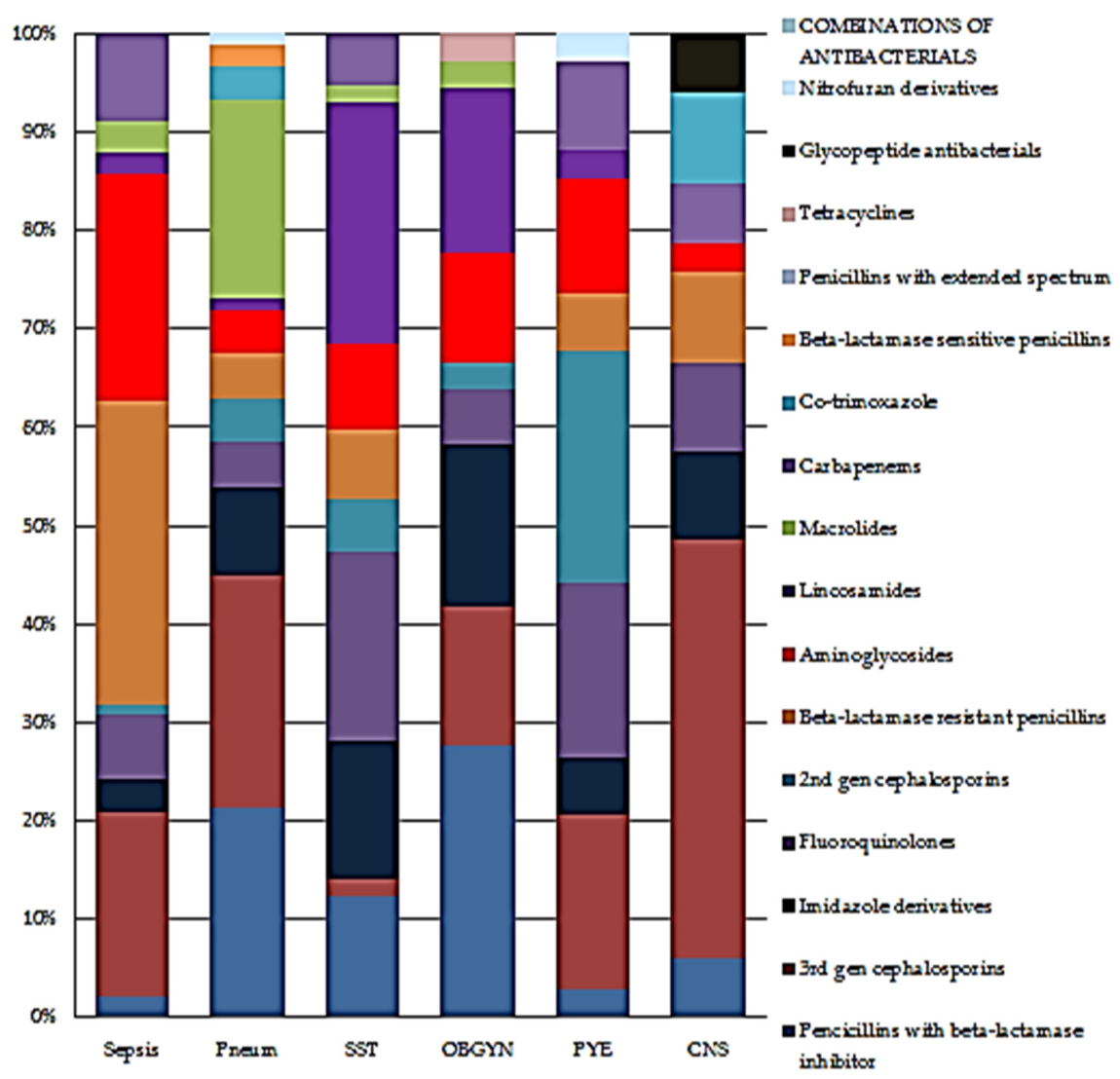

Figure 2. Top 6 indications disaggregated by antibiotic class. Abbreviations: Pneu: pneumonia or lower respiratory tract infection, SST: skin and soft tissue, OBGY: obstetric/gynaecological infections, Pye: upper urinary tract infection, CNS: infection of central nervous system.

\section{Discussion}

This was a comprehensive antimicrobial PPS that involved all clinical departments, wards and units of the KBTH. Data collection was carried out over a 3-day period, and all patients' folders were assessed. Data were collected on those patients on at least one antimicrobial agent during the survey period.

\subsection{Antimicrobial Prevalence}

This survey identified an overall prevalence of antimicrobial prescriptions among inpatients at the Korle Bu Teaching Hospital to be 53.3\%. Among the inpatients surveyed, $83.5 \%$ of them received systemic antimicrobials and $65 \%$ received more than one antimicrobial. The prevalence rate in this study is comparable to previous studies performed in KBTH among inpatients which found prevalence rates of 51.4\% in 2006 [25] and 53\% in 2000 [26]. This shows that rates of antibiotic use among inpatients in KBTH have been fairly consistent over the past two decades. Studies from other hospitals in Ghana showed comparatively higher prevalence rates with Komfo Anokye Teaching Hospital reporting a prevalence of 64\% [27]; Ho Teaching Hospital recorded 66.7\% [28], and Keta Municipal Hospital recorded $82.0 \%$ [29]. Prevalence from this study compared favourably with antimicrobial prevalence in Africa (63\%) but is still relatively high compared to North America (34.0\%), South Europe (31.7\%) or East Europe (30.3\%) [16]. Higher rates of antimicrobial use are typically linked with the development of antimicrobial resistance and healthcare-associated infections [30] and thus must be suitably justified. 


\subsection{Most Common Antimicrobials Prescribed}

The top four antibiotics prescribed, metronidazole, amoxicillin/clavulanic acid, ceftriaxone and cefuroxime, reinforce the work of Labi et al. [25] which reported the same antibiotics as the four most used antibiotics at the Korle Bu Teaching Hospital. Beta-lactam antibiotics (cephalosporins and penicillins) were the most frequently used classes. Fluoroquinolones were more frequently prescribed than macrolides and aminoglycosides. The antibiotic use pattern found in this study is largely consistent with those of recently published point prevalence survey of antibiotics [16,31-33] These results suggest that beta lactam antibiotics remain drugs of choice in the management of infections. The usefulness of this group of antibiotics in the future is however threatened, as data show that increased antibiotic use is associated with antimicrobial resistance [34-39].

\subsection{Most Common Diagnosis for Antimicrobial Use}

The top three morbidities requiring antimicrobial therapy in the hospital were pneumonia, skin and soft tissue infections and sepsis with upper respiratory tract infections and malaria as the fourth and fifth topmost respectively. The results are similar to a study carried out in a referral hospital in Kenya in which the respiratory system had the largest proportion of antibiotics prescribed followed by skin, soft tissue, bone and joint (SSTBJ) infections [32]. It is also quite similar to a survey carried out in 18 hospitals in Egypt, in which amongst patients receiving antibiotics for treatment of infection, the most common anatomical sites of suspected or proven infection were the respiratory tract, gastrointestinal tract, and skin, bone and joints [40].

Further, in a survey involving paediatric patients from 26 Canadian hospitals, the most commonly treated infections were sepsis $(16 \%)$ and lower respiratory tract infection (12.1\%) [41]. The consistency in these results may justify the prescribing of these medicines; however, care should be taken to avoid over prescribing.

\subsection{Targeted versus Empiric Treatment}

Most treatments were empirical for both healthcare- and community-acquired infections. This finding is consistent with recent data from Africa [42] and other developing countries $[43,44]$. Empirical treatment for community-acquired infections had a higher proportion compared to empirical treatment for healthcare-acquired infections. Versporten et al. published similar findings [16]. Empirical treatment of infections can be attributed to limited laboratory resources to aid in the identification of specific pathogens and the antimicrobials they are most susceptible to. This results in the use of broad-spectrum empiric treatment in a bid to cover all possible pathogens that could be responsible for the infection. In a randomized comparative prospective study of complications in transrectal prostate biopsy [44] post-prophylactic treatment, it was found that infection rates were significantly lower in targeted treatment compared to empirical treatment. Further, the supremacy of targeted treatment over empirical treatment was manifested in a meta-analysis [45]. The increased empirical treatment of infections in the hospital may contribute to the burden of a microorganism. While it has been reported that tertiary hospitals in Ghana perform better in targeted treatment of infections compared to non-tertiary (secondary) settings [29], results from this study implies that targeted treatment needs more improvement. The hospital's Drugs and Therapeutics Committee may lead the way in this regard.

\subsection{Quality Indicators for Prescribing}

In this era of increasing AMR, policies that seek to promote prudent antimicrobial prescribing have been developed and adopted by countries and hospitals [46]. An evidencebased antimicrobial guideline is preferably the mainstay of such policies [47]. Adherence to such hospital guidelines is however often low to moderate [48,49]. Korle bu Teaching hospital had some positive practices regarding antimicrobial stewardship among the indicators evaluated, but this varied widely by ward type. Guideline compliance was greater than $80 \%$ among all the wards surveyed, and this was quite laudable. However, 
when it came to documenting the reasons for antimicrobial prescriptions, the medical wards fared much better than the surgical or ICU $(76.1 \%$ vs. $44.3 \%$ vs. $41.2 \%$ respectively). Possible reasons for these results could be the focus of future studies.

Another important indicator for prudent antimicrobial prescribing is the presence of a stop or review date. Here, the ICU fell short compared to the surgical and medical wards ( $11.8 \%$ vs. $49.9 \%$ vs. $38.5 \%$, respectively). A possible reason for this could be the daily review of patients on the ICU wards, hence prescribers not appreciating the need to indicate the stop or review date. An intervention targeting ICU prescribers to include this parameter in their notes will be important for KBTH to improve antimicrobial stewardship.

Considering biomarkers, patients pay per laboratory tests that are not reimbursed; hence, c-reactive protein (CRP) and procalcitonin are often viewed as non-essential expensive extras.

Point prevalence surveys are among the most reliable tools in the assessment of antibiotic utilization at the patient level [50]. They are also valuable in providing information on antimicrobial resistance. Access to antimicrobial utilization and resistance patterns are pivotal for the success of any antimicrobial stewardship (AMS) programme. In a systematic review and meta-analysis, a significant association was reported between an AMS programme and a decrease in the incidence of antibiotic infections among hospitalized patients [51]. This calls for regular PPS at all health institutions with the aim of identifying the gaps and fixing them to improve public health.

\subsection{Limitations}

Data collection in this study was performed over three days only. The seasonal nature of some diseases (asthma, flu, etc.) that require the use of antimicrobial agents may change the prevalence of figures depending on the time the study is performed. This calls for continuous PPS at different times in the year before the actual antimicrobial prevalence in the hospital can be determined. For Ghana, there are only two clear seasons (rainy season and dry season), and the effect may not be as significant compared to countries with four seasons. It is possible that reported figures for microbiological reports may be less than actual because these may have been absent during the survey period, most probably due to the time it takes for such reports to be ready. We did not report on the number of various laboratory tests (blood culture, stools for $C$. difficile, etc.) performed per year, to avoid under ascertainment. This is because some of the requested tests were performed in private labs outside the hospital.

\section{Materials and Methods}

\subsection{Study Design}

A cross-sectional study design was used to investigate antimicrobial use and resistance among all inpatients at the Korle Bu Teaching Hospital from the 19-21 June 2019. The primary outcome was to understand antimicrobial prescribing rates, antimicrobial indications and agent selection. The secondary outcome was to look at key prescribing indicators and resistance rates, if available.

\subsubsection{Study Site}

The point prevalence survey was based at the Korle Bu Teaching Hospital, Accra. The Korle $\mathrm{Bu}$ is a teaching hospital affiliated with the University of Ghana Medical School. It is currently the third largest Hospital in Africa and the leading national referral centre for Ghana and beyond, including the National Reconstructive Plastic Surgery and Burn Centre, the National Cardiothoracic Centre and the National Centre for Radiotherapy and Nuclear Medicine.

The Hospital has a 2000-bed capacity, with an average daily attendance of 1500 outpatients and approximately 250 patient admissions. There are 17 clinical and diagnostic departments/units including all branches of medicine and surgery, including neurosurgery, 
radiotherapy and oncology, paediatric surgery, dentistry, psychiatry, ophthalmology, child health and obstetrics and gynaecology.

\subsubsection{Pre-Survey}

Eleven pharmacists and 8 intern pharmacists underwent a 2-day training workshop in June 2019, covering the foundations of antimicrobial surveillance and the global-PPS methodology [31]. The training was conducted by a consultant microbiologist and an antimicrobial pharmacist from the North Middlesex University Hospital, London, UK.

\subsubsection{Study Population}

All patients on all wards in the hospital admitted at $08: 00 \mathrm{~h}$ on the day of the survey formed the baseline population of the survey (denominator).

\subsubsection{Sampling Method}

Patient folders and medication charts were screened for eligibility. For inpatients receiving at least one antimicrobial, detailed information was collected using standardized data collection forms (http:/ / www.global-pps.com, accessed on 1 June 2019).

\subsubsection{Inclusion Criteria}

Inclusion criteria as per the global-PPS: all inpatients on any antibiotic before 8 am on the day of the survey; patients hospitalized as an inpatient at or before 08:00 h; antibiotic administered orally, parenterally, rectally or through inhalation; ongoing treatment at 08:00 $\mathrm{h}$. In addition, for surgical patients, the dosage and time of administration of prophylactic antimicrobials before or after surgery were obtained to determine the duration and frequency of prophylaxis.

\subsubsection{Exclusion Criteria}

Exclusion criteria as per the global-PPS: hospitalized after 08:00 h, outpatient clinic, day surgery/day treatment, emergency room, outpatient dialysis, discharged patients waiting for transportation, parents/relatives of admitted children, outpatient parenteral antibiotic therapy (OPAT), topical antibiotics, ophthalmologic antibiotics, treatment initiated after 08:00 h, treatment discontinued before 08:00 h.

\subsection{Data Collection}

Pharmacists and interns were divided into groups and dispatched to departments. Ward level data was captured, including information on the type of ward, number of eligible patients, and characteristics of the ward. Patient level data included information on the antimicrobial agents prescribed, indication, laboratory data, stop/review date and other quality indicators. Guideline compliance was according to the National Ghana treatment guidelines or local treatment guidelines if applicable. For this study, the Standard Treatment Guideline of the Ghana National Drugs Programme [52] (GNDP) as well as the local guideline at the department of obstetrics and gynaecology were used. All data collection forms were centrally validated to ensure consistency across groups. Using the 5 moments of hand hygiene, train-the-trainer sessions on infection prevention and control (IPC) were organized, followed by hand hygiene audits and instant feedback. The report on IPC is being handled separately from the PPS report.

\subsection{Data Entry}

Collected data were entered into a web-based tool for data entry and validation designed by the University of Antwerp (http:/ / global-pps.com, accessed on 1 June 2019) by two data analysts with oversight from the United Kingdom partners. 


\subsection{Data Analysis}

Validated data were exported to Microsoft Excel and analysed with Microsoft Excel 2016. We examined antimicrobial utilization and assessed percentage adherence/compliance to health policy guidelines. Further, we assessed levels of targeted and empirical treatment against health care associated infections (HAI) defined as "infection detected within $48 \mathrm{~h}$ of hospital admission in patients that had previous contact with healthcare service within one year", and community acquired infections (CAI), defines as "infection detected within $48 \mathrm{~h}$ of hospital admission in patients without previous contact with healthcare service" [53]. In addition, we ascertained morbidities that were treated using antimicrobial agents. These were based on agreed quality indicators from the GPPSS instrument used (See Supplementary Material S1).

\subsection{Ethical Issues}

Ethical approval was not sought, as this was a quality improvement project that needs to be performed continuously.

Supplementary Materials: The following are available online at https://www.mdpi.com/article/10. 3390/antibiotics10121528/s1.

Author Contributions: All authors made significant contributions. These include, conceptualization, E.B., D.A., J.M. and M.M.; methodology, D.A., J.M. and M.M.; software, M.M., A.O., A.A. (Asiwome Aggor), H.O. and P.E.; validation, O.A., L.L. and S.A.; formal analysis, D.A. and M.M.; investigation, M.M., J.M., A.A. (Agnetta Ampomah) and F.N.; resources, M.H., E.B. and G.O.A.; data curation, G.O.A. and J.S.; writing—original draft preparation, D.A., J.L., P.E., M.H. and H.O.; writing-review and editing, A.A. (Agnetta Ampomah), J.M., F.N. and O.A.; visualization, D.A. and A.O.; supervision, D.A. and M.M.; project administration, A.A. (Asiwome Aggor) and J.L.; funding acquisition, D.A. and M.M. All authors have read and agreed to the published version of the manuscript.

Funding: This project and partnership was part of the Commonwealth Partnerships for Antimicrobial Stewardship (CwPAMS) managed by the the Tropical Health Education Trust (THET) and Commonwealth Pharmacists Association (CPA). CwPAMS is a global health partnership programme funded by the Department of Health and Social Care (DHSC) using UK aid funding, managed by the Fleming Fund. The Fleming Fund is a $£ 265$ million UK aid investment to tackle AMR by supporting low- and middle-income countries to generate, use and share data on AMR and is managed by the UK Department of Health and Social Care.

Institutional Review Board Statement: This was a quality improvement project that needs to be performed continuously. Ethical approval was not sought but there was a memorandum of understanding with the Korle-Bu Teaching Hospital management.

Informed Consent Statement: There was no contacts with patients in this study and hence no need for informed consent.

Data Availability Statement: Data from this point prevalent survey are included in the study.

Acknowledgments: We thank Daniel Asare (CEO of KBTH), the CEO of North Middlesex University Hospital (NMUH) and all officials and staff of the KBTH who assisted in diverse ways to ensure success of this comprehensive PPS. We thank all those who assisted in the data collection and the data entry, particularly Pharm Philip Amui, Pharm Esther Jackson, Pharm Aryee Adjavon, Pharm Jonathan Doku, Pharm Yaa Pokua, Pharm Owusu Senyah, and Pharm Reginald Sekyi-Brown. We recognize the role played by Ann Versporten and Ines Pauwels, from the University of Antwerp, Belgium in ensuring the success of this survey. Finally, we would like to thank the Pharmaceutical Society of Ghana for giving us timely information on the availability of the grant from THET. The Global Point Prevalence Survey is coordinated at the University of Antwerp, Belgium and sponsored through an unrestricted grant given to them by bioMérieux and personal Methusalem grant to Herman Goossens from the Flemish government. 
Conflicts of Interest: The views expressed in this publication are those of the authors and not necessarily those of the UK National Health Service, the Department of Health and Social Care, Tropical Health and Education Trust or The Commonwealth Pharmacists Association. All authors have no conflict of interest to declare.

\section{References}

1. Gelband, H.; Molly Miller, P.; Pant, S.; Gandra, S.; Levinson, J.; Barter, D.; White, A.; Laxminarayan, R. The State of the World's Antibiotics 2015; Center for Disease Dynamics, Economics and Policy: Washington, DC, USA, 2015.

2. O'Neill, J. Review on Antimicrobial Resistance: Tackling Drug-Resistant Infections Globally: Final Report and Recommendations; Wellcome Trust: London, UK, 2016.

3. European Centre for Disease Prevention and Control, European Medicines Agency. The Bacterial Challenge: Time to React. A Call to Narrow the Gap between Multidrug-Resistant Bacteria in the EU and the Development of New Antibacterial Agents. Available online: https://www.ema.europa.eu/en/news/bacterial-challenge-time-react-call-narrow-gap-between-multidrug -resistant-bacteria-eu-development (accessed on 1 December 2021).

4. da Costa, M.E.; Machado, H.S. Evolution of antimicrobial resistance in Europe: A factual review. J. Allergy Ther. $2017,8,2$.

5. World Health Organization. Antimicrobial Resistance Global Report on Surveillance: 2014 Summary. Available online: https: / /apps.who.int/iris/bitstream/handle/10665/112647/WHO_HSE_PED_AIP_?sequence=1 (accessed on 1 December 2021).

6. Le Doare, K.; Bielicki, J.; Heath, P.T.; Sharland, M. Systematic review of antibiotic resistance rates among gram-negative bacteria in children with sepsis in resource-limited countries. J. Pediatric Infect. Dis. Soc. 2015, 4, 11-20. [CrossRef] [PubMed]

7. Leopold, S.J.; van Leth, F.; Tarekegn, H.; Schultsz, C. Antimicrobial drug resistance among clinically relevant bacterial isolates in sub-Saharan Africa: A systematic review. J. Antimicrob. Chemother. 2014, 69, 2337-2353. [CrossRef]

8. GARP-Tanzania National Working Group. Situation Analysis and Recommendations: Antibiotic Resistance in Tanzania; Dar es Salaam, Tanzania, 2015. Available online: https://cddep.org/publications/garp_tanzania_situation_analysis/ (accessed on 3 March 2021).

9. Vandepitte, J.; Hughes, P.; Matovu, G.; Bukenya, J.; Grosskurth, H.; Lewis, D.A. High prevalence of ciprofloxacin-resistant gonorrhea among female sex workers in Kampala, Uganda (2008-2009). Sex. Transm. Dis. 2014, 41, 233-237. [CrossRef]

10. Kariuki, S.; Gordon, M.A.; Feasey, N.; Parry, C.M. Antimicrobial resistance and management of invasive Salmonella disease. Vaccine 2015, 33, C21-C29. [CrossRef]

11. Kariuki, S.; Gichia, M.; Kakai, R. Situation Analysis: Antibiotic Use and Resistance in Kenya; The GARP-Kenya National Working Group; Kenya Medical Research Institute: Nairobi, Kenya, 2011; Available online: https://cddep.org/wp-content/uploads/201 7/08/garp-kenya_es.pdf (accessed on 1 December 2021).

12. HPSC Annual Epidemiological Reports 2014. European Antimicrobial Resistance Surveillance Network (EARS-Net). EARS-Net Report; Ireland. Available online: https:/ / www.hpsc.ie/a-z/microbiologyantimicrobialresistance/europeanantimicrobialresis tancesurveillancesystemearss/ears-netdataandreports/annualreports/File,15531,en.pdf (accessed on 6 June 2021).

13. O'Neill, J. Antimicrobial Resistance: Tackling a Crisis for the Health and Wealth of Nations. 2014. Available online: https: / / amr-review.org/sites/default/files/AMR\%20Review\%20Paper\%20-\%20Tackling\%20a\%20crisis\%20for\%20the \%20health\%2 0and\%20wealth\%20of\%20nations_1.pdf. (accessed on 3 March 2021).

14. Van Boeckel, T.P.; Gandra, S.; Ashok, A.; Caudron, Q.; Grenfell, B.T.; Levin, S.A.; Laxminarayan, R. Global antibiotic consumption 2000 to 2010: An analysis of national pharmaceutical sales data. Lancet Infect. Dis. 2014, 14, 742-750. [CrossRef]

15. Onwueme, K.; Fadairo, Y.; Idoko, L.; Onuh, J.; Alao, O.; Agaba, P.; Lawson, L.; Ukomadu, C.; Idoko, J. High prevalence of toxinogenic Clostridium difficile in Nigerian adult HIV patients. Trans. R. Soc. Trop. Med. Hyg. 2011, 105, 667-669. [CrossRef]

16. Versporten, A.; Zarb, P.; Caniaux, I.; Gros, M.F.; Drapier, N.; Miller, M.; Jarlier, V.; Nathwani, D.; Goossens, H.; Koraqi, A.; et al. Antimicrobial consumption and resistance in adult hospital inpatients in 53 countries: Results of an internet-based global point prevalence survey. Lancet Glob. Health 2018, 6, e619-e629. [CrossRef]

17. Newman, M.J.; Frimpong, E.; Donkor, E.S.; Opintan, J.A.; Asamoah-Adu, A. Resistance to antimicrobial drugs in Ghana. Infect. Drug Resist. 2011, 4, 215.

18. Nweneka, C.V.; Tapha-Sosseh, N.; Sosa, A. Curbing the menace of antimicrobial resistance in developing countries. Harm Reduct. J. 2009, 6, 1-4. [CrossRef] [PubMed]

19. Harbarth, S.; Balkhy, H.H.; Goossens, H.; Jarlier, V.; Kluytmans, J.; Laxminarayan, R.; Saam, M.; Van Belkum, A.; Pittet, D. Antimicrobial Resistance: One World, One Fight! Antimicrob. Resist. Infect. Control. 2015, 4. [CrossRef]

20. World Health Organization. Global Antimicrobial Resistance Surveillance System (GLASS) Report: Early Implementation 2016-2017. Available online: https:/ /apps.who.int/iris/bitstream/handle/10665/259744/9789241513449-eng.pdf (accessed on 1 December 2021).

21. Barlam, T.F.; Cosgrove, S.E.; Abbo, L.M.; MacDougall, C.; Schuetz, A.N.; Septimus, E.J.; Srinivasan, A.; Dellit, T.H.; Falck-Ytter, Y.T.; Fishman, N.O.; et al. Implementing an antibiotic stewardship program: Guidelines by the Infectious Diseases Society of America and the Society for Healthcare Epidemiology of America. Clin. Infect. Dis. 2016, 62, e51-e77. [CrossRef]

22. Davey, P.; Brown, E.; Charani, E.; Fenelon, L.; Gould, I.M.; Holmes, A.; Ramsay, C.R.; Wiffen, P.J.; Wilcox, M. Interventions to improve antibiotic prescribing practices for hospital inpatients. Cochrane Database Syst. Rev. 2013, 4, eCD003543. [CrossRef] 
23. Schuts, E.C.; Hulscher, M.E.; Mouton, J.W.; Verduin, C.M.; Stuart, J.W.; Overdiek, H.W.; van der Linden, P.D.; Natsch, S.; Hertogh, C.M.; Wolfs, T.F.; et al. Current evidence on hospital antimicrobial stewardship objectives: A systematic review and meta-analysis. Lancet Infect. Dis. 2016, 16, 847-856. [CrossRef]

24. ECDC. Point Prevalence Survey of Healthcare-Associated Infections and Antimicrobial Use in European Acute Care Hospitals; European Centre for Disease Prevention and Control: Stockholm, Sweden, 2013; Available online: https:/ / ecdc.europa.eu/en/healthcare-a ssociated-infections-acute-care-hospitals (accessed on 12 November 2018).

25. Labi, A.-K.; Obeng-Nkrumah, N.; Nartey, E.T.; Bjerrum, S.; Adu-Aryee, N.A.; Ofori-Adjei, Y.A.; Yawson, A.E.; Newman, M.J. Antibiotic use in a tertiary healthcare facility in Ghana: A point prevalence survey. Antimicrob. Resist. Infect. Control 2018, 7, 15. [CrossRef]

26. Newman, M.J. Nosocomial and community acquired infections in Korle Bu teaching hospital, Accra. West Afr. J. Med. 2009, 28, 300-303. [CrossRef]

27. ECTMIH 2017 (Poster N 5P95): Global Point Prevalence Survey on Antimicrobial Use and Resistance (Global-PPS): Implications for Antibiotic Stewardship Programme for Komfo Anokye Teaching Hospital in Ghana. Available online: https://www.globalpp s.com/wp-content/uploads/ECTMIH-2017-5P95-Ghana.pdf (accessed on 11 August 2021).

28. Dodoo, C.C.; Orman, E.; Alalbila, T.; Mensah, A.; Jato, J.; Mfoafo, K.A.; Folitse, I.; Hutton-Nyameaye, A.; Okon Ben, I.; MensahKane, P.; et al. Antimicrobial Prescription Pattern in Ho Teaching Hospital, Ghana: Seasonal Determination Using a Point Prevalence Survey. Antibiotics 2021, 10, 199. [CrossRef]

29. Afriyie, D.K.; Sefah, I.A.; Sneddon, J.; Malcolm, W.; McKinney, R.; Cooper, L.; Kurdi, A.; Godman, B.; Seaton, R.A. Antimicrobial point prevalence surveys in two Ghanaian hospitals: Opportunities for antimicrobial stewardship. Jac Antimicrob. Resist. 2020, 2, 1-9. [CrossRef]

30. Iosifidis, E.; Antachopoulos, C.; Tsivitanidou, M.; Katragkou, A.; Farmaki, E.; Tsiakou, M.; Kyriazi, T.; Sofianou, D.; Roilides, E. Differential correlation between rates of antimicrobial drug consumption and prevalence of antimicrobial resistance in a tertiary Care Hospital in Greece. Infect. Control Hosp. Epidemiol. 2008, 29, 615-622. [CrossRef]

31. Vandael, E.; Latour, K.; Goossens, H.; Magerman, K.; Drapier, N.; Catry, B.; Versporten, A.; The Belgian Point Prevalence Survey Study Group. Point prevalence survey of antimicrobial use and healthcare associated infections in Belgian acute care hospitals: Results of the Global-PPS and ECDC-PPS, 2017. Antimicrob. Resist. Infect. Control 2020, 9, 13. [CrossRef]

32. Momanyi, L.; Opanga, S.; Nyamu, D.; Oluka, M.; Kurdi, A.; Godman, B. Antibiotic prescribing pattern at a leading referral hospital in Kenya: A Point Prevalence Survey. J. Res. Pharm Pr. 2019, 8, 149-154. [CrossRef]

33. Laxminarayan, R.; Heymann, D.L. Challenges of drug resistance in the developing world. BMJ 2012, 344, e1567. [CrossRef]

34. Goossens, H.; Ferech, M.; Vander Stichele, R.; Elseviers, M.; The ESAC Project Group. Outpatient antibiotic use in Europe and association with resistance: A cross-national database study. Lancet 2005, 365, 579-582. [CrossRef]

35. Megraud, F.; Coenen, S.; Versporten, A.; Kist, M.; Lopez-Brea, M.; Hirschl, A.M.; Andersen, L.P.; Grossens, H.; Glupczynski, Y. Helicobacter pylori resistance to antibiotics in Europe and it's relationship to antibiotic consumption. Gut 2013, 62, 34-42. [CrossRef] [PubMed]

36. Shorr, A.F. Epidermiology of Staphylococcal resistance. Clin. Infect. Dis. 2007, 45, S171-S176. [CrossRef]

37. Moran, G.J.; Krishnadasan, A.; Gorwitz, R.J.; Forscheim, G.E.; McDougal, L.K.; Carey, R.B.; Talan, D.A. Methicillin resistant S. Aureus infections among patients in the emergency department. N. Eng. J. Med. 2006, 355, 66674. [CrossRef]

38. Opinta, J.A.; Newman, M.J.; Arhin, R.E.; Donkor, E.S.; Gyansa-Lutterodt, M.; Mills-Pappoe, W. Laboratory-based nationwide surveillance of antimicrobial resistance in Ghana. Infect. Drug Resist. 2015, 8, 379. [CrossRef] [PubMed]

39. Anand Paramadhas, B.D.; Tiroyakgosi, C.; Mpinda-Joseph, P.; Morokotso, M.; Matome, M.; Sinkala, F.; Gaolebe, M.; Malone, B.; Molosiwa, E.; Shanmugam, M.G.; et al. Point Prevalence study of antimicrobial use among hospitals across Botswana; findings and implications. Expert Rev. Anti-Infect. 2019, 17, 535-546. [CrossRef]

40. Talaat, M.; Saied, T.; Kandeel, A.; El-Ata, G.A.A.; El-Kholy, A.; Hafez, S.; Osman, A.; Razik, M.A.; Ismail, G.; El-Masry, S.; et al. A point prevalence survey of antibiotic use in 18 hospitals in Egypt. Antibiotics 2014, 3, 450-460. [CrossRef]

41. Lefebvre, M.A.; Versporten, A.; Carrier, M.; Chang, S.; Comeau, J.L.; Emond, Y.; Frenette, C.; Khan, S.; Landry, D.L.; MacLaggab, T.D.; et al. The 2018 Global Point Prevalence Survey of Antimicrobial Consumption and Resistance: Pediatric Results from 26 Canadian Hospitals. Open Forum Infect. 2019, 9, 1-9.

42. Porto, A.P.; Goossens, H.; Versporten, A.; Costa, S.F. Brazilian Global-PPS Working Group. Global point prevalence of antimicrobial consumption in Brazilian hospitals. J. Hosp. Infect. 2020, 1014, 165-171. [CrossRef]

43. Zivanovic, V.; Gojkovic-Bukarica, L.; Scepanovic, R.; Vitorovic, T.; Novakovic, R.; Milanov, N.; Bukumiric, Z.; Carevic, B.; Trajkovic, J.; Rajkovic, J.; et al. Differences in antimicrobial consumption, prescribing and isolation rate of multidrug resistant Klebsiella pneumonia, Pseudomonas aeruginosa and Acinetobacter baumannii on surgical and medical wards. PLoS ONE 2017, 12, e0175689. [CrossRef]

44. Doherty, A.F.; Ikuerowo, S.O.; Jeje, E.A.; Ibrahim, N.A.; Ojongbede, O.L.; Mutiu, W.B.; Omisanjo, O.A.; Abolarinwa, A.A. A Prospective Randomized Comparative Study of Targeted versusEmpirical Prophylactic Antibiotics in the Prevention of Infective Complications following Transrectal Ultrasound-Guided ProstateBiopsy. Ann. Afr. Med. 2019, 18, 132-137. [PubMed]

45. Roberts, M.J.; Williamson, D.A.; Hadway, P.; Suhail ARDoi, S.A.R.; Gardiner, R.A.; Paterson, D.L. Baseline prevalence of antimicrobial resistance and subsequent infection following prostate biopsy using empirical or altered prophylaxis: A biasadjusted meta-analysis. Int. J. Antimicrob. Agents 2014, 43, 301-309. [CrossRef] [PubMed] 
46. Gould, I.M. A review of the role of antibiotic policies in the control of antibiotic resistance. J. Antimicrob. Chemother. 1999, 43, 459-465. [CrossRef] [PubMed]

47. Fijn, R.; Chow, M.C.; Schuur, P.M.; De Jong-Van den Berg, L.T.; Brouwers, J.R. Multicentre evaluation of prescribing concurrence with anti-infective guidelines: Epidemiological assessment of indicators. Pharm. Drug Saf. 2002, 11, 361-372. [CrossRef] [PubMed]

48. Halm, E.A.; Atlas, S.J.; Borowsky, L.H.; Benzer, T.I.; Metlay, J.P.; Chang, Y.C.; Singer, D.E. Understanding physician adherence with a pneumonia practice guideline: Effects of patient, system, and physician factors. Arch. Intern. Med. 2000, 160, 98-104. [CrossRef]

49. Van de Beek, D.; de Gans, J.; Spanjard, L.; Vermeulen, M.; Dankert, J. Antibiotic guidelines and antibiotic use in adult bacterial meningitis in the Netherlands. J. Antimicrob. Chemother. 2002, 49, 661-666. [CrossRef]

50. Global Point Prevalence Survey on Antimicrobial Consumption and Resistance. Global-PPS Website. Available online: http: / / www.global-pps.com/ (accessed on 30 November 2021).

51. Baur, D.; Gladstone, B.P.; Burkert, F.; Carrara, E.; Foschi, F.; Döbele, S.; Tacconelli, E. Effect of antibiotic stewardship on the incidence of infection and colonisation with antibiotic-resistant bacteria and Clostridium difficile infection: A systematic review and meta-analysis. Lancet Infect. Dis. 2017, 17, 990-1001. [CrossRef]

52. Standard Treatment Guidelines. Ghana National Drugs Programme. Ministry of Health. Seventh Edition. 2017. Available online: https:/ / www.moh.gov.gh/wp-content/uploads/2020/07/GHANA-STG-2017-1.pdf (accessed on 12 November 2021).

53. Cardoso, T.; Almeida, M.; Friedman, N.D.; Aragão, I.; Costa-Pereira, A.; Sarmento, A.E.; Azevedo, L. Classification of healthcareassociated infection: A systematic review 10 years after the first proposal. BMC Med. 2014, 12, 40. [CrossRef] [PubMed] 